\title{
Dietary rhubarb (Rheum rhaponticum ) stalk fibre does not lower plasma cholesterol levels in diabetic rats
}

\author{
Sukhinder Kaur Cheema ${ }^{1,2}$, Vinti Goel ${ }^{3}$, Tapan K. Basu ${ }^{3}$ and Luis B. Agellon ${ }^{1}$ \\ ${ }^{1}$ Department of Biochemistry, University of Alberta, Edmonton, Alberta, Canada T6G 2S2 \\ ${ }^{2}$ Department of Biochemistry, Memorial University of Newfoundland, St. John's, Newfoundland, Canada A1B $3 X 9$ \\ ${ }^{3}$ Department of Agricultural, Food and Nutritional Sciences, University of Alberta, Edmonton, Alberta, Canada T6G $2 P 5$
}

(Received 15 February 2002 - Revised 9 September 2002 - Accepted 22 September 2002)

\begin{abstract}
Rhubarb (Rheum rhapontiam) stalk fibre was previously shown to be hypolipidaemic under clinical and experimental conditions. The present study was undertaken to investigate whether rhubarb stalk fibre has a hypolipidaemic effect under diabetic conditions. Two models of diabetic rats were used: streptozotocin-induced diabetic rats, and diabetes-prone BB (BBdp) rats. The plasma cholesterol and triacylglycerol concentrations were elevated after the onset of diabetes in BBdp rats, but not in sterptozotocin-induced diabetic rats. The rhubarb-fibre diet had no effect on the plasma cholesterol or triacylglycerol concentrations of diabetic rats. The hypolipidaemic effect of rhubarb stalk fibre has been suggested to be due to the bile-acid-binding capacity of rhubarb fibre, which in turn up regulates cholesterol $7 \alpha$-hydroxylase (cyp7a) activity. cyp7a is the first and the rate-limiting enzyme in the breakdown of cholesterol to bile acids. We measured the cyp7a activity and mRNA levels in control and diabetic rats fed rhubarb- and cellulose-fibre diets. The cyp7a activity and mRNA abundance were increased in both diabetic rat models, indicating that bile acid synthesis is enhanced in diabetes. Feeding a diet enriched with rhubarb fibre caused a slight but significant increase $(P<0.05)$ in cyp7a enzyme activity in BBdp rats, but no change in cyp7a mRNA abundance was detected. These results suggest that although a rhubarb-fibre-enriched diet increased cyp7a activity in BBdp rats, there was no apparent therapeutic benefit in terms of lowering plasma cholesterol concentrations.
\end{abstract}

Diabetes: Rhubarb (Rheum rhapontioum ) stalk fibre: Cholesterol $7 \alpha$-hydroxylase

Diabetes mellitus is a common disorder and a leading cause of morbidity and mortality all over the world. Diabetes is characterized as a disease of carbohydrate metabolism; however, abnormalities of lipid and lipoprotein metabolism are commonly observed in this disorder. Hyperlipidaemia (Brown, 1994), arteriosclerosis (Kessler, 1971) and gallstones (Turrill et al. 1961) are frequently associated with diabetes, indicating alterations in cholesterol metabolism in this disease (Turrill et al. 1961; Bennion \& Grundy, 1977). Research during the last few years has emphasized the role of plasma lipid and lipoprotein metabolism in the development of atherosclerosis in diabetes; however, the mechanisms explaining the association between diabetes and atherosclerosis are still unknown.

The liver is the major site for cholesterol catabolism, where cholesterol is converted to bile acids. The excretion of bile acids and cholesterol via bile is the main route for elimination of cholesterol from the body. The major pathway responsible for the synthesis of bile acids is initiated by the microsomal enzyme cholesterol $7 \alpha$-hydroxylase (cyp7a) (Agellon \& Torchia, 2000). In diabetes, the bile acid pool is significantly expanded, characterized mainly by a rise in cholic acid content (Nervi et al. 1978; Uchida et al. 1979; Kimura et al. 1992). The size of the bile acid pool is normalized by insulin therapy, suggesting that insulin might regulate bile acid metabolism (Bennion \& Grundy, 1977; Nervi et al. 1978; Kimura et al. 1988). Studies using cultured hepatocytes have shown the suppression of the cyp7a gene expression by insulin (Twisk et al. 1995). However, studies using animal models of type 1 and type 2 diabetes have yielded conflicting results with regard to regulation of cyp7a gene expression (Uchida et al. 1979; Subbiah \& Yunker, 1984; Hansson, 1989). 
Dietary-fibre type has significant influence on plasma cholesterol and glucose concentrations. Current recommendations for the dietary management of diabetes mellitus include increasing the consumption of dietary fibre. Insoluble fibre, such as cellulose, is non-viscous and/or non-fermentable and has limited capacity to lower plasma cholesterol concentrations (Gallaher et al. 1993). On the other hand, rhubarb (Rheum raponticum) fibre, a predominantly insoluble fibre, lowers plasma cholesterol concentrations in animals fed a high-cholesterol diet (Basu et al. 1993) and in hypercholestrolaemic human subjects (Goel et al. 1997). Rhubarb fibre contains $80 \mathrm{~g}$ pectin $/ \mathrm{kg}$, a soluble fibre with a known cholesterol-lowering capacity (Fernandez, 1995). Rhubarb fibre was found to bind bile acids (Goel et al. 1997); feeding diets enriched in rhubarb fibre to C57BL/6J mice increased the excretion of bile acids and increased cyp7a activity (Goel et al. 1999). Since bile acid levels are significantly increased under diabetic conditions, the aim of the present study was: (1) to assess the expression of the cyp7a gene in two animal models of diabetes namely, the diabetes-prone BB (BBdp) rat and the streptozotocin-induced diabetic rat; (2) to investigate whether feeding a diet rich in rhubarb fibre is beneficial in lowering plasma cholesterol levels in diabetic rats. Two models of diabetic rats were used to investigate whether streptozotocin-induced diabetic rats and BBdp rats differ in the regulation of bile acid metabolism and in their response to dietary-fibre type.

\section{Materials and methods}

\section{Animals and diets}

Male BBdp rats $(250-310 \mathrm{~g}, 6-7$ weeks old) were obtained from Health Canada (Animal Resources Division, Health Protection Branch, Ottawa, Ont., Canada). BBdp rats were diabetic upon arrival from Health Canada; diabetes was re-confirmed upon arrival by blood glucose concentrations measured from tail bleeds using a glucometer. Rats with blood glucose concentrations $>2.00 \mathrm{~g} / \mathrm{l}$ were considered diabetic. Male Sprague-Dawley rats (240$280 \mathrm{~g}, 6-7$ weeks old) were obtained from the University of Alberta Health Sciences colony. Animals were housed individually in a temperature- and humidity-controlled room with $12 \mathrm{~h}$ light-dark cycle. The use of animals in this study was approved by the University of Alberta Animal Welfare Committee. All animals were given a rodent chow diet and water ad libitum before the start of the experimental diets. The experimental diets varied in the fibre source, containing either $50 \mathrm{~g}$ cellulose or $50 \mathrm{~g}$ rhubarb stalk fibre $/ \mathrm{kg}$. The diet composition is given in Table 1.

After the animals had acclimatized to the experimental diets for $3 \mathrm{~d}$, diabetes was induced in Sprague-Dawley rats by intravenous injection of streptozotocin $(20 \mathrm{mg} / \mathrm{kg}$ body weight; Sigma-Aldrich Chemical Co., St Louis, MO, USA) in an acetate buffer ( $\mathrm{pH} 4.5)$. The age-matched control Sprague-Dawley rats and the BBdp rats received a sham injection of the acetate buffer to control for any additional effects of the acetate buffer in streptozotocininduced diabetic rats. Tail bleeds were performed $24 \mathrm{~h}$
Table 1. Composition $(\mathrm{g} / \mathrm{kg})$ of the diets containing rhubarb (Rheum rapontioum) stalk fibre on cellulose

\begin{tabular}{lcc}
\hline & \multicolumn{2}{c}{ Diet } \\
\cline { 2 - 3 } Ingredient $^{*}$ & Rhubarb & Cellulose \\
\hline Casein & 200 & 200 \\
L-Methionine & 2 & 2 \\
Starch & 648 & 648 \\
Vitamin mix & 10 & 10 \\
Mineral mix & 30 & 30 \\
Maize oil & 60 & 60 \\
Fibreł & 50 & 50
\end{tabular}

*Ingredients were from ICN Biomedicals, Cleveland, OH, USA.

†Supplied in quantities adequate to meet National Research Council (1995) requirements.

$\ddagger$ Cellulose was supplied as Alphacel non-nutritive bulk (ICN Biomedicals Inc., Aurora, OH, USA). Rhubarb stalk fibre was prepared at the University of Alberta, Department of Agricultural, Food Science and Nutrition.

after streptozotocin injection and blood glucose concentrations were measured using a glucometer. Animals with blood glucose concentrations of $>2.00 \mathrm{~g} / \mathrm{l}$ were considered diabetic. The streptozotocin-induced diabetic rats, BBdp rats and control rats were fed the experimental diets for 2 weeks. The food intake and body weight were measured once per week. The animals were fasted overnight at the end of the 2 week period on the experimental diets. A tail-nick blood sample was taken for fasting blood glucose in the morning. The blood and tissue samples were collected as mentioned later.

\section{Blood and tissue analyses}

On day 15 (after the tail nicks to collect blood for fasting blood glucose concentrations), the animals were anaesthetized, blood was collected via cardiac puncture into a syringe containing EDTA $(1 \mathrm{~g} / \mathrm{l})$ and plasma was separated. Plasma insulin concentrations were determined using a commercial double-antibody radioimmunoassay kit (Linco Research, St Louis, MO, USA) for rat insulin. Plasma glucose levels were determined using Sigma Diagnostics Glucose (Trinder) reagent (Sigma Aldrich Diagnostics, St. Louis, MO, USA) for the enzymatic determination of glucose. The livers were removed and stored at $-70^{\circ} \mathrm{C}$ prior to analysis. Lipids were extracted from liver samples as described previously (Yokode et al. 1990). Liver extracts and plasma samples were assayed for total cholesterol and triacylglycerol content using enzymatic methods (kit no. 352 for total cholesterol and kit no. 339 for triacylglycerols; Sigma-Aldrich Diagnostics). Hepatic free-cholesterol content was determined by enzymatic methods (kit no. 274-47109; Wako Chemicals USA, Inc., Richmond, VA, USA).

\section{Determination of cholesterol $7 \alpha$-hydroxylase enzyme activity and $m R N A$ abundance}

Microsomes were prepared from liver homogenates as previously described (Cheema et al. 1997). Microsomal cyp7a activity ( $\mathrm{pmol} / \mathrm{min}$ per $\mathrm{mg}$ protein) was measured following the conversion of $\left[{ }^{14} \mathrm{C}\right]$ cholesterol to $7 \alpha$-hydroxy$\left[{ }^{14} \mathrm{C}\right]$ cholesterol as described previously (Agellon, 1997). 
To detect changes in cyp7a mRNA abundance, total RNA from rat livers was purified according to standard procedures (Chomczynski \& Sacchi, 1987). Hepatic cyp7a mRNA levels were determined by a ribonuclease protection assay. Total RNA $(20 \mu \mathrm{g})$ was hybridized with ${ }^{32} \mathrm{P}$-labelled cDNA probes for cyp7a (cyp7a gene from exon 3; $228 \mathrm{nt}$ plus $71 \mathrm{nt}$ from intron 2) and glyceraldehyde-3-phosphate dehydrogenase (pTRI-GAPDH, Ambion catalogue no. 7431; Ambion, Austin, TX, USA) at $55^{\circ} \mathrm{C}$ overnight. Unhybridized probes were removed by treatment with RNAse One (4 U/ $\mu$ g RNA) (Promega Biotech, Madison, WI, USA) for $1 \mathrm{~h}$ at $25^{\circ} \mathrm{C}$. The protected mRNA fragments were separated on denaturing polyacrylamide $(50 \mathrm{~g} / \mathrm{kg}) \mathrm{gel}$. The radioactivity in each band was quantitated by phosphorautoradiography using Fuji-X BAS 1000 plate imager (Fuji, Richmond, Ont., Canada). The amount of cyp7a mRNA was normalized to glyceraldehyde-3-phosphate dehydrogenase mRNA content.

\section{Statistical analysis}

The effects of diabetes and diets were assessed by ANOVA. Values are group mean with their standard errors for eight rats per group. Differences were considered to be statistically significant if the associated $P$ value was $<0.05$ (Steel \& Torrie, 1980).

\section{Results}

\section{Food intake and body-weight gain}

The food intake did not differ between groups. Animals consumed 26.1 (SE 0.5) and 26.1 (SE 0.9) g celluloseand rhubarb-fibre diets/d respectively. There was no significant difference in body-weight gain during the study between the animals fed cellulose or rhubarb-fibre diet. However, at day 14, streptozotocin-induced diabetic animals fed ad libitum had a greater body-weight gain than the control and BBdp rats $(2.4$ (SE 0.6) g $v$. no bodyweight gain).

\section{Blood variables}

Plasma insulin levels were significantly lower $(P<0.05)$ for BBdp rats and streptozotocin-induced diabetic rats compared with control animals (Table 2). Among diabetic animals, the BBdp rats had lower insulin levels than streptozotocin-induced diabetic rats. Fasting plasma glucose concentrations were significantly higher $(P<0.05)$ in streptozotocin-induced and $\mathrm{BBdp}$ rats than control rats (Table 2 ). The BBdp rats had greater plasma glucose levels than streptozotocin-induced diabetic rats fed either the cellulose or rhubarb-fibre diet. The lower insulin levels and higher plasma glucose concentrations in both diabetic models confirm onset of diabetes. Neither of the dietary fibres used in the diets had an effect on plasma insulin or glucose levels (Table 2).

\section{Plasma and hepatic cholesterol}

The plasma cholesterol and triacylglycerol levels were greater in BBdp rats than the control and streptozotocininduced diabetic rats (Table 3). Dietary-fibre source had no significant influence on the plasma cholesterol or triacylglycerol levels. Hepatic total cholesterol and triacylglycerol concentrations were lower in streptozotocin-induced diabetic rats and BBdp rats than control rats (Table 4). Feeding a diet enriched in rhubarb fibre significantly lowered the hepatic total cholesterol and triacylglycerol concentrations $(P<0.01)$ in control as well as diabetic rats (Table 4). However, dietary-fibre source or disease state had no effect on liver microsomal free-cholesterol content (Table 4).

\section{Hepatic cholesterol $7 \propto$-hydroxylase activity and $m R N A$ abundance}

The cyp7a enzyme activity was significantly greater in the diabetic rats than control rats (Fig. 1). The streptozotocininduced diabetic rats showed a slight but significant increase in cyp7a activity compared with control rats (1.3-fold increase on cellulose diet and 1.5-fold increase on rhubarb-fibre diet, $P<0.05)$. The BBdp rats had a much greater increase in cyp7a activity than control rats $(P<0.001)$. The increase in cyp7a enzyme activity under diabetic conditions was paralleled by an increase in cyp7a mRNA (Fig. 2). There was a slight but significant increase in cyp7a mRNA abundance in streptozotocininduced diabetic rats compared with control rats $(1 \cdot 8$-fold increase, $P<0.05)$. The BBdp rats had a much greater

Table 2. Fasting glucose and insulin concentrations in the plasma of diabetic rats* (Mean values and standard deviations for eight rats per group)

\begin{tabular}{|c|c|c|c|c|c|c|c|c|}
\hline \multirow[b]{3}{*}{ Group } & \multicolumn{4}{|c|}{ Glucose (g/l) } & \multicolumn{4}{|c|}{ Insulin (mU/l) } \\
\hline & \multicolumn{2}{|c|}{ Cellulose $†$} & \multicolumn{2}{|c|}{ Rhubarb† } & \multicolumn{2}{|c|}{ Cellulose† } & \multicolumn{2}{|c|}{ Rhubarb† } \\
\hline & Mean & SD & Mean & SD & Mean & SD & Mean & SD \\
\hline Control & $0.84^{c}$ & 0.08 & $0.79^{c}$ & 0.07 & $0.82^{a}$ & 0.08 & $0.88^{a}$ & 0.03 \\
\hline STZ rats & $3.07^{b}$ & 0.77 & $2 \cdot 83^{\mathrm{b}}$ & 0.6 & $0.48^{\mathrm{b}}$ & 0.06 & $0.55^{\mathrm{b}}$ & 0.05 \\
\hline BBdp rats & $4 \cdot 39^{a}$ & 0.45 & $4 \cdot 21^{a}$ & 0.44 & $0.21^{c}$ & 0.05 & $0.27^{c}$ & 0.10 \\
\hline
\end{tabular}

STZ, streptozotocin-induced diabetic rats; BBdp, diabetes-prone BB rats

${ }^{\star}$ For details of diets and procedures, see Table 1 and p. 202

$\dagger$ Rats were fed the diets indicated for 2 weeks.

${ }_{a, b, c}$ Mean values within a column with unlike superscript letters were significantly different (ANOVA): $P<0.05$. 
Table 3. Total cholesterol and triacylglycerol concentrations in the plasma of diabetic rats* (Mean values and standard deviations for eight rats per group)

\begin{tabular}{|c|c|c|c|c|c|c|c|c|}
\hline \multirow[b]{3}{*}{ Group } & \multicolumn{4}{|c|}{ Total cholesterol $(\mathrm{mmol} / \mathrm{l})$} & \multicolumn{4}{|c|}{ Total triacylglycerol (mmol/l) } \\
\hline & \multicolumn{2}{|c|}{ Cellulose† } & \multicolumn{2}{|c|}{ Rhubarb $†$} & \multicolumn{2}{|c|}{ Cellulose† } & \multicolumn{2}{|c|}{ Rhubarb $†$} \\
\hline & Mean & SD & Mean & SD & Mean & SD & Mean & SD \\
\hline Control & $1.50^{\mathrm{b}}$ & 0.38 & $1.58^{\mathrm{b}}$ & 0.33 & $1 \cdot 15^{\mathrm{b}}$ & 0.56 & $1.15^{\mathrm{b}}$ & 0.41 \\
\hline STZ rats & $1.74^{\mathrm{b}}$ & 0.36 & $1.61^{\mathrm{b}}$ & 0.41 & $1 \cdot 32^{b}$ & 0.28 & $1.30^{\mathrm{c}}$ & 0.27 \\
\hline BBdp rats & $2 \cdot 63^{\mathrm{a}}$ & 0.22 & $2.68^{\mathrm{a}}$ & 0.27 & $1.84^{\mathrm{a}}$ & 0.87 & $2 \cdot 17^{\mathrm{a}}$ & 0.80 \\
\hline
\end{tabular}

STZ, steptozotocin-induced diabetic rats; BBdp, diabetes-prone BB rats.

${ }^{*}$ For details of diets and procedures, see Table 1 and p. 202.

†Rats were fed the diets indicated for 2 weeks.

a,b,c Mean values within a column with unlike superscript letters were significantly different (ANOVA):

$P<0.05$.

increase in cyp7a mRNA levels than control and streptozotocin-induced diabetic rats (5-fold increase, $P<0 \cdot 001$ ). Although the cyp7a enzyme activity was significantly greater $(P<0.05)$ under diabetic conditions, indicating breakdown of cholesterol to bile acids, there was no effect on plasma cholesterol concentrations.

Feeding a diet enriched in rhubarb fibre increased the cyp7a activity only in BBdp rats $(P<0.001)$ compared with BBdp rats fed the cellulose diet (Fig. 1). There was no effect of dietary-fibre source on cyp7a mRNA abundance in control or diabetic rats.

\section{Discussion}

Plasma cholesterol and triacylglycerol concentrations are significantly elevated under diabetic conditions, a cause for increased incidence of cardiovascular disease. Current recommendations on dietary management of diabetes include increasing dietary fibre intake. Certain types of fibre lower plasma cholesterol concentrations by binding to bile acids, thus acting as bile acid sequestrants to lower plasma cholesterol concentrations. Bile-acid pool size is significantly increased under diabetic conditions (Nervi et al. 1978; Uchida et al. 1979; Kimura et al. 1992). However, the correlation between increased bileacid pool size in diabetes and onset of cardiovascular disease is not known. We have previously shown that feeding the rhubarb-fibre diet lowered plasma cholesterol and triacylglycerol levels in C57BL/6J mice, and that the decrease in plasma cholesterol concentrations is due to the bile-acid-binding capacity of rhubarb stalk fibre (Goel et al. 1997). In the current study, we investigated whether feeding the rhubarb-stalk-fibre diet to diabetic animals lowers plasma cholesterol concentrations.

The mechanism of the regulation of bile acid metabolism under diabetic conditions, especially the regulation of cyp7a, the rate-limiting enzyme in the synthesis of bile acids, is highly controversial (Uchida et al. 1979; Subbiah \& Yunker, 1984). Controversy regarding cyp7a regulation is likely to be due to differences in drug dosage and route of drug delivery to induce diabetes in animals. To overcome this problem, we used two rat models that develop diabetes via different mechanisms to gain an insight into the regulation of bile acid metabolism under diabetic conditions.

Feeding the rhubarb-fibre diet had not significant effect on plasma total cholesterol and triacylglycerol levels. However, the hepatic total cholesterol and triacylglycerol concentrations were significantly lower $(P<0.05)$ in control as well as in diabetic animals fed a diet rich in rhubarb fibre. Rhubarb stalk fibre, a predominantly insoluble fibre capable of binding bile acids (Goel et al. 1998), lowers plasma cholesterol levels in mice fed high-cholesterol diets, and also in hypercholesterolaemic humans subjects (Goel et al. 1997). Feeding the rhubarb-fibre diet to both rat models of diabetes had no significant effect on plasma total cholesterol and triacylglycerol levels, although the hepatic total cholesterol and triacylglycerol

Table 4. Hepatic total cholesterol, total triacylglycerol and microsomal free-cholesterol concentrations of diabetic rats* (Mean values and standard deviations for eight rats per group)

\begin{tabular}{|c|c|c|c|c|c|c|c|c|c|c|c|c|}
\hline \multirow[b]{3}{*}{ Group } & \multicolumn{4}{|c|}{ Total cholesterol $(\mu \mathrm{mol} / \mathrm{g})$} & \multicolumn{4}{|c|}{ Total triacylglycerol $(\mu \mathrm{mol} / \mathrm{g})$} & \multicolumn{4}{|c|}{ Free cholesterol $(\mu \mathrm{mol} / \mathrm{g})$} \\
\hline & \multicolumn{2}{|c|}{ Cellulose $†$} & \multicolumn{2}{|c|}{ Rhubarb $†$} & \multicolumn{2}{|c|}{ Cellulose† } & \multicolumn{2}{|c|}{ Rhubarb $†$} & \multicolumn{2}{|c|}{ Cellulose $†$} & \multicolumn{2}{|c|}{ Rhubarb $†$} \\
\hline & Mean & SD & Mean & SD & Mean & SD & Mean & SD & Mean & SD & Mean & SD \\
\hline Control & $16 \cdot 8^{a}$ & 3.0 & $7 \cdot 0^{c}$ & 0.9 & $0.98^{a}$ & 0.08 & $0.71^{\mathrm{b}}$ & 0.04 & $0.45^{a}$ & 0.03 & $0.49^{a}$ & 0.04 \\
\hline STZ rats & $12 \cdot 0^{\mathrm{b}}$ & 3.0 & $5 \cdot 4^{d}$ & 0.7 & $0.80^{\mathrm{b}}$ & 0.07 & $0.56^{d}$ & 0.04 & $0.49^{a}$ & 0.04 & $0.44^{a}$ & 0.02 \\
\hline BBdp rats & $8.5^{\mathrm{c}}$ & 1.0 & $4 \cdot 4^{d}$ & 0.8 & $0.68^{\mathrm{C}}$ & 0.04 & $0.38^{\mathrm{e}}$ & 0.02 & $0.42^{a}$ & 0.04 & $0.46^{a}$ & 0.04 \\
\hline
\end{tabular}

STZ, streptozotocin-induced diabetic rats; BBdp, diabetes-prone BB rats.

${ }^{*}$ For details of diets and procedures, see Table 1 and p. 202.

† Rats were fed the diets indicated for 2 weeks.

a,b,c,d,e Mean values within a column with unlike superscript letters were significantly different (ANOVA): $P<0.05$. 


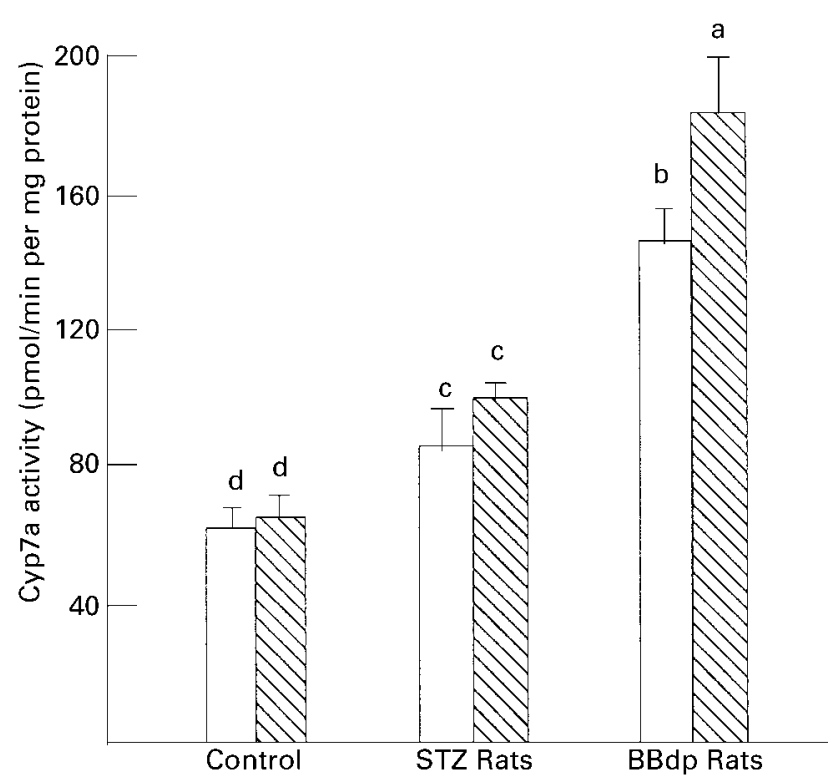

Fig. 1. The effects of dietary cellulose fibre ( $\square$ ) and rhubarb (Rheum raponticum) stalk fibre $(\mathbb{Q})(50 \mathrm{~g} / \mathrm{kg})$ on the cholesterol $7 \alpha-$ hydroxylase (cyp7a) enzyme activity in control, streptozotocininduced (STZ) and diabetes-prone BB (BBdp) rats. Values are means for eight animals, with standard deviations shown by vertical bars. For details of diets and procedures, see Table 1 and p. 202. $a, b, c, d$ Mean values with unlike superscript letters were significantly different: $P<0.05$.

concentrations were significantly reduced $(P<0 \cdot 05)$ by feeding the rhubarb-fibre diet to control as well as to diabetic animals. In our previous study, we observed that rhubarb stalk fibre decreased plasma and hepatic cholesterol concentrations only when mice were fed a high-fat and high-cholesterol diet (Goel et al. 1999). It is not clear why rhubarb stalk fibre is ineffective when animals are fed low-cholesterol diets or when given to diabetic animals. Other dietary-fibre sources, such as psyllium and USP, were also found to have a cholesterol-lowering effect only when given in the presence of dietary cholesterol (Abbey et al. 1993; Horton et al. 1994). These dietary fibres, when fed together with cholesterol, increase the LDL-receptor expression in guinea pigs, thereby leading to increased uptake of LDL and lowering plasma cholesterol levels (Fernandez et al. 1992). The mechanism of the regulation of hepatic LDL-receptor activity by rhubarb fibre under diabetic conditions is not known. The reduction in hepatic total cholesterol and triacylglycerol concentrations by rhubarb fibre is intriguing. We did not measure the acetyl-CoA:cholesterol acyltransferase activity, hydroxymethylglutaryl-Co reductase activity or the fatty acid synthesis in these animals. It is likely that rhubarb stalk fibre alters one of these enzymes, thereby leading to decrease in the synthesis and/or storage of cholesterol and triacylglycerol in the liver.

Our results on the regulation of bile acid metabolism under diabetic conditions indicate that cyp7a enzyme activity and mRNA levels are significantly greater $(P<0.05)$ in both streptozotocin-induced and BBdp rats compared with control animals. The increase in cyp7a activity and mRNA levels is likely to be responsible for the expanded bile-acid pool size under diabetic conditions.

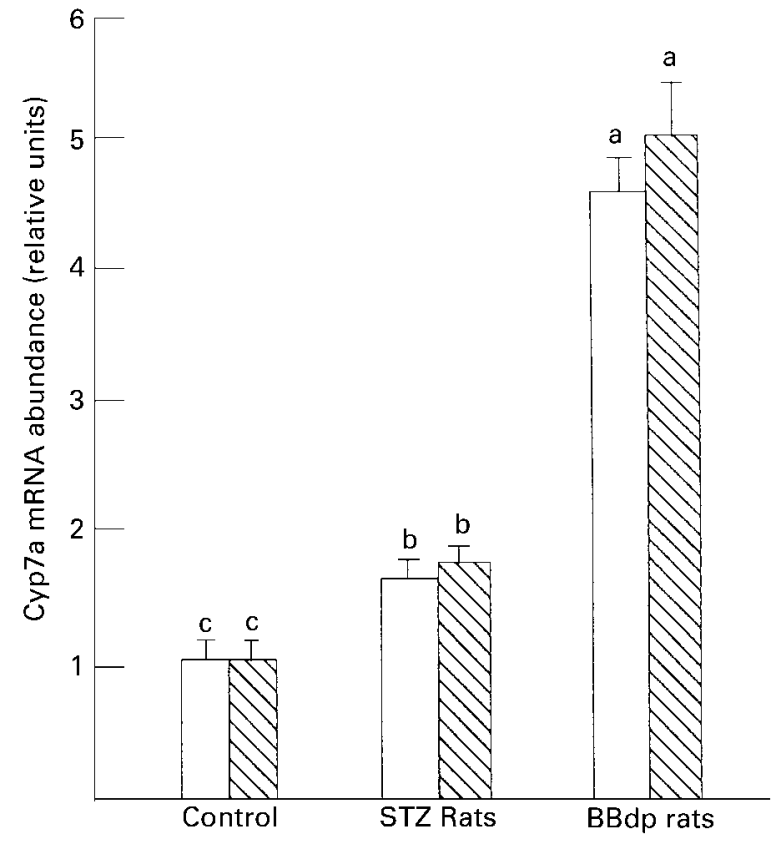

Fig. 2. The effects of dietary cellulose fibre ( $\square$ ) and rhubarb (Rheum raponticum) stalk fibre $(\mathbb{\mathbb { N }})(50 \mathrm{~g} / \mathrm{kg})$ on the cholesterol $7 \alpha-$ hydroxylase (cyp7a) mRNA abundance in control, streptozotocininduced (STZ) and diabetes-prone BB (BBdp) rats. Values are means for eight animals, with standard deviations shown by vertical bars. For details of diets and procedures, see Table 1 and p. 202 a,b,c Mean values with unlike superscript letters were significantly different: $P<0.05$.

The plasma cholesterol concentrations are high under diabetic conditions despite the increase in cyp7a activity. Several studies have reported an increase in intestinal hydroxymethylglutanyl-CoA reductase activity in druginduced diabetic rats (Nakayama \& Nakagawa, 1977; Young et al. 1982; Feingold et al. 1994). As bile acids aid the absorption of cholesterol, it is likely that the increased bile-acid pool size under diabetic conditions increases the absorption of dietary and endogenously synthesized cholesterol, leading to an increase in plasma cholesterol concentrations.

Increasing the bile-acid pool size by feeding diets supplemented whit bile acids down regulates cyp7a gene expression (Torchia et al. 1996). Since the pool of bile acids in the enterohepatic circulation of diabetic rats is increased in diabetes, it is surprising to find an enhancement of cyp7a gene expression. One possibility is that the recovery of bile acids in the intestine is decreased under diabetic conditions, thereby reducing the flux of bile acids through the liver. The activity of intestinal bile acid transporters under diabetic conditions is not well characterized. However, it is reported that bile flow is significantly reduced in both drug-induced and spontaneously diabetic rats (Gonzalez \& Fevery, 1992).

In conclusion, the results of the present study suggest that the expression in bile-acid pool size in streptozotocininduced and in BBdp rats is associated with the stimulation of cyp7a gene expression, leading to a significant increase $(P<0.05)$ in cyp7a activity. The results further indicate 
that feeding a diet containing $50 \mathrm{~g}$ rhubarb stalk fibre $/ \mathrm{kg}$ for 2 weeks has no beneficial effects in terms of lowering plasma cholesterol levels under diabetic conditions. It is possible that feeding rhubarb fibre for 2 weeks is not long enough to see an effect on plasma cholesterol levels, so future studies will involve long-term feeding trials.

\section{Acknowledgements}

This research was supported by a grant from the Canadian Institutes of Health Research (MGP 14812). S. K. C. holds a New Investigator Award from the Canadian Institutes of Health Research. L. B. A. is a Senior Scholar of the Alberta Heritage Foundation for Medical Research.

\section{References}

Abbey M, Triantafilidis C \& Topping DL (1993) Dietary nonstarch polysaccharides interact with cholesterol and fish oil in their effects on plasma lipids and hepatic lipoprotein receptor activity in rats. Journal of Nutrition 123, 900-908.

Agellon LB (1997) Partial transfection of liver with a synthetic cholesterol $7 \alpha$-hydroxylase transgene is sufficient to stimulate the reduction of cholesterol in the plasma of hypercholesterolemic mice. Biochemistry and Cell Biology 75, 255-262.

Agellon LB \& Torchia EC (2000) Intracellular transport of bile acids. Biochimica et Biophysica Acta 1486, 198-209.

Basu TK, Ooraikul B \& Garg M (1993) The lipid lowering effects of rhubarb stalk fibre: a new source of dietary fibre. Nutrition Research 13, 1017-1024.

Bennion LJ \& Grundy SM (1977) Effects of diabetes mellitus on cholesterol metabolism in man. New England Journal of Medicine 296, 1365-1371.

Brown WV (1994) Lipoprotein disorders in diabetes mellitus. Medical Clinics of North America 78, 143-161.

Cheema SK, Cikaluk D \& Agellon LB (1997) Dietary fats modulate the regulatory potential of dietary cholesterol on cholesterol $7 \alpha$-hydroxylase gene expression. Journal of Lipid Research 38, 315-323.

Chomczynski P \& Sacchi N (1987) Single-step method of RNA isolation by acid guanidinium thiocyanate-phenol-chloroform extraction. Analytical Biochemistry 162, 156-158.

Feingold KR, Wilson DE, Wood LC, Kwong LK, Moser AH \& Grunfeld C (1994) Diabetes increases hepatic hydroxymethyl glutaryl coenzyme A reductase protein and mRNA levels in the small intestine. Metabolism 43, 450-454.

Fernandez ML (1995) Distinct mechanisms of plasma LDL lowering by dietary fibre in the guinea pig: specific effects of pectin, guar gum and psyllium. Journal of Lipid Research 36, 2394-2404.

Fernandez ML, Lin EC, Trejo A \& McNamara DJ (1992) Prickly pear (Opuntia sp.) pectin reverses low density lipoprotein receptor suppression induced by a hypercholesterolemic diet in guinea pigs. Journal of Nutrition 122, 2330-2340.

Gallaher DD, Hassel CA, Lee KJ \& Gallaher CM (1993) Viscosity and fermentability as attributes of dietary fibre responsible for hypocholesterolemic effect in hamsters. Journal of Nutrition 123, 244-252.

Goel V, Cheema SK, Agellon LB, Ooraikul B \& Basu TK (1999) Dietary rhubarb (Rheum rhaponticum) stalk fibre stimulates cholesterol $7 \alpha$-hydroxylase gene expression and bile acid excretion in cholesterol-fed C57BL/6J mice. British Journal of Nutrition 81, 65-71.
Goel V, Cheema SK, Agellon LB, Ooraikul B, McBurney MI \& Basu TK (1998) In vitro binding of bile salt to rhubarb stalk powder. Nutrition Research 18, 893-903.

Goel V, Ooraikul B \& Basu TK (1997) Cholesterol lowering effects of rhubarb fibre in hypercholesterolemic men. Journal of American College of Nutrition 16, 600-604.

Gonzalez J \& Fevery J (1992) Spontaneously diabetic biobreeding rats and impairment of bile acid-independent bile flow and increased biliary bilirubin, calcium and lipid secretion. Hepatology 16, 426-432.

Hansson R (1989) Effect of diabetes, starvation, ethanol and isoniazid on rat liver microsomal $12 \alpha$-hydroxylase activity involved in bile acid biosynthesis. Biochemical Pharmacology 38, 3386-3389.

Horton JD, Cuthbert JA \& Spady DK (1994) Regulation of hepatic $7 \alpha$-hydroxylase expression by dietary psyllium in the hamster. Journal of Clinical Investigation 93, 2084-2092.

Kessler II (1971) Mortality experience of diabetic patients: a twenty-six year follow-up study. American Journal of Medicine 51, 715-724.

Kimura K, Ogura Y \& Ogura M (1988) Increased rate of cholic acid formation from 3 alpha, 7 alpha-dihydroxy- 5 beta-cholestane in perfused livers from diabetic rats. Biochimica et Biophysica Acta 963, 329-332.

Kimura K, Ogura Y \& Ogura M (1992) Biosynthesis of cholic acid accelerated by diabetes: its mechanism and effect of vanadate administration. Biochimica et Biophysica Acta 1123, 303-308.

Nakayama H \& Nakagawa S (1977) Influence of streptozotocin diabetes on intestinal 3-hydroxy-3-methylglutaryl coenzyme A reductase activity in the rat. Diabetes 26, 439-444.

National Research Council (1995) Nutrient requirements of laboratory animals, 4th revised ed., pp. 11-79. Washington, DC: The National Academic Press.

Nervi FO, Severin CH \& Valdivieso VD (1978) Bile acid pool changes and regulation of cholate synthesis in experimental diabetes. Biochimica et Biophysica Acta 529, 212-223.

Steel RGD \& Torrie JH (1980) Principles and Procedures of Statistics: A Biometrical Approach, pp. 67-119. New York: McGraw-Hill.

Subbiah MTR \& Yunker RL (1984) Cholesterol $7 \alpha$-hydroxylase of rat liver: an insulin sensitive enzyme. Biochemical and Biophysical Research Communications 124, 896-902.

Torchia EC, Cheema SK \& Agellon LB (1996) Coordinate regulation of bile acid biosynthetic and recovery pathways. Biochemical and Biophysical Research Communications 255, $128-133$.

Turrill EL, McCarron MM \& Mikkelson WP (1961) Gallstone and diabetes, ominous association. American Journal of Surgery 102, 184-190.

Twisk J, Hoekman FM, Lehman EM, Meijer P, Mager WH \& Princen HMG (1995) Insulin suppresses bile acid synthesis in cultured hepatocytes by down regulation of cholesterol $7 \alpha-$ hydroxylase and sterol 27-hydroxylase gene transcription. Hepatology 21, 501-510.

Uchida K, Takase H, Kadowaki M, Nomura Y, Matsubara T \& Takeuchi N (1979) Altered bile acid metabolism in alloxan diabetic rats. Japanese Journal of Pharmacology 29, 553-562.

Yokode M, Hammer RE, Ishibashi S, Brown MS \& Goldstein JL (1990) Diet induced hypercholesterolemia in mice: prevention by overexpression of LDL receptors. Science 250, 1273-1275.

Young NL, Saudek CD \& Crawford SA (1982) Total hydroxymethylglutaryl CoA reductase activity in the small intestine and liver of insulin-deficient rats. Journal of Lipid Research 23, 266-275. 